\title{
Demografia do perfilhamento e acúmulo de matéria seca em coastcross submetido a pastejo(1)
}

\author{
Carlos Augusto Brandão de Carvalho(2), Sila Carneiro da Silva ${ }^{(3)}$, André Fischer Sbrissia( ${ }^{(2)}$, Luiz Felipe de Moura Pinto(4),
} Roberta Aparecida Carnevalli(4), Jailson Lara Fagundes ${ }^{(4)}$ e Carlos Guilherme Silveira Pedreira(3)

\begin{abstract}
Resumo - Os objetivos deste trabalho foram identificar o padrão populacional do perfilhamento de coastcross (Cynodon spp. cv. Coastcross) sob pastejo, e avaliar o acúmulo de matéria seca de sua forragem. Foram avaliados densidade populacional, taxas de natalidade e mortalidade de perfilhos, proporção de perfilhos florescidos e acúmulo de matéria seca. Os tratamentos consistiram em manter a altura do pasto em 5, 10, 15 e $20 \mathrm{~cm}$, utilizando ovinos sob regime de lotação contínua e taxa de lotação variável. Pastos mais baixos $(5 \mathrm{~cm})$ apresentaram as maiores densidades populacionais de perfilhos. O florescimento foi mais intenso durante o final do inverno e início da primavera. Ocorreu alta renovação de perfilhos durante o verão. As condições de seca promoveram fortes efeitos sobre as taxas de natalidade e de mortalidade de perfilhos. Não houve efeito $(\mathrm{P}>0,10)$ de tratamento sobre as taxas de acúmulo de matéria seca.
\end{abstract}

Termos para indexação: Cynodon, florescimento, cultivo de pastos, população de plantas.

Tiller demography and dry matter accumulation in coastcross grass under grazing

\begin{abstract}
The aim of this study was to identify patterns of tiller dynamics and to evaluate herbage dry matter accumulation in Coastcross Bermudagrass (Cynodon spp. cv. Coastcross) swards under grazing. Pasture responses evaluated were: tiller population density, tiller natality and mortality rates, proportion of flowering tillers and accumulation of herbage dry matter for Cynodon spp. cv. Coastcross. Experimental treatments corresponded to four steady state conditions characterized by sward surface heights of $5,10,15$, and $20 \mathrm{~cm}$ maintained by sheep under continuous stocking and variable stocking rate. The shortest sward $(5 \mathrm{~cm})$ showed the highest tiller population density. The flowering was intense late winter and early spring. A high turnover in tiller population was observed during summer. A dry spell in November caused a decrease in tiller natality and increase in mortality rates. There was no treatment effect $(\mathrm{P}>0.10)$ on rates of herbage dry matter accumulation.
\end{abstract}

Index terms: Cynodon, flowering, herbage crops, plant population.

\section{Introdução}

As gramíneas forrageiras utilizam o perfilhamento como forma de crescimento, incremento em produti-

(1) Aceito para publicação em 20 de junho de 2000 .

Extraído da dissertação de mestrado apresentada pelo primeiro autor à Escola Superior de Agricultura Luiz de Queiroz (ESALQ), Piracicaba, SP. Financiado pela FAPESP.

(2)ESALQ, Dep. de Produção Animal, Caixa Postal 09 CEP 13418-900 Piracicaba, SP. Bolsista da FAPESP. E-mail: sbrissia@bol.com.br

(3)ESALQ, Dep. de Produção Animal. E-mail: scdsilva@carpa.ciagri.usp.br, cgspedre@esalq.usp.br

(4)ESALQ, Dep. de Produção Animal. Bolsista da CAPES E-mail: omazzo@bol.com.br, racarnev@carpa.ciagri.usp.br, ratinhoj1@yahoo.com.br vidade e, sobretudo, sobrevivência da comunidade de plantas em pastagens estabelecidas (Hodgson, 1990). O estudo do comportamento dessa característica fenológica de gramíneas forrageiras tem ocorrido de forma intensa há muitos anos, inclusive na atualidade, nos países ditos avançados quanto à utilização racional de plantas forrageiras (Matthew et al., 1999). Tal fato se justifica pelas estratégias de manejo idealizadas com base nessas investigações terem gerado consistentemente incremento em produtividade das pastagens (Silva, 1994). Porém, em países como o Brasil, ainda em processo de evolução quanto a estratégias de utilização das pastagens, investigações nesse assunto ainda são incipientes e necessitam de maiores esforços por parte dos pesquisadores (Silva \& Pedreira, 1997). 
O nascimento de perfilhos ocorre em virtude de diversos estímulos fisiológicos e/ou de ambiente, e é controlado primariamente pelo genótipo de cada espécie forrageira (Mitchell, 1953). Sua potencialidade é dependente tanto da geração (nascimento) de novas gemas (pontos de crescimento) basais ou laterais, como da velocidade com que cada uma se desenvolve, formando um novo perfilho (Mitchell, 1953). Em uma mesma planta, o nascimento de perfilhos parece ser geneticamente programado, uma vez que cada nova folha formada contém uma nova gema na base de sua axila (Jewiss, 1972). Contudo, a integração entre as condições de ambiente, os níveis hormonais e a fase de desenvolvimento fenológico das plantas é que regula a intensidade e localização do desenvolvimento das gemas (Jewiss, 1972; Gautier et al., 1999). A natalidade de perfilhos deve ser sempre estimulada, principalmente em períodos onde ocorram grandes mortalidades (alto "turnover") a fim de assegurar boa produtividade e perenidade do pasto.

Em gramíneas, com exceção a algumas espécies de dias neutros e outras sujeitas à vernalização, o florescimento é controlado pelo comprimento do dia, ou seja, pelo fotoperíodo. Contudo, alguns outros fatores de ambiente são necessários para completar a resposta das plantas ao fotoperíodo (Langer, 1963). Ao final do período reprodutivo, o perfilho morre, uma vez que atinge o final de seu ciclo natural de vida, tempo este que pode variar de poucas semanas até mais de um ano (Langer, 1956). Perfilhos morrem nas pastagens segundo uma série de eventos que podem estar relacionados com sombreamento, florescimento, pastejo severo, pisoteio, deposição de fezes e urina, e predação por insetos (L'Huillier, 1987). A principal causa da morte de perfilhos vegetativos é o sombreamento, em virtude do desenvolvimento do dossel (Colvill \& Marshall, 1984). Já os perfilhos ditos reprodutivos morrem principalmente em decorrência do pastejo, pois mesmo que uma pequena porção do caule seja pastejada nessa fase do desenvolvimento fenológico, o perfilho como um todo morre (Chapman et al., 1984).

As taxas de nascimento, florescimento e morte de perfilhos determinam sua contribuição para a composição botânica do relvado, de forma a permitir maior ou menor acúmulo de forragem em diferentes épocas do ano (Langer, 1963; Korte, 1986). O reconhecimento da variação em padrões populacionais de perfilhos fornece base para um "ajuste fino" dos sistemas de manejo de pastejo, que pode levar a incrementos na produtividade das pastagens (Matthew et al., 1999).

Os objetivos deste trabalho foram identificar o padrão populacional de perfilhamento de coastcross sob pastejo, e avaliar o acúmulo de matéria seca de forragem.

\section{Material e Métodos}

O experimento foi realizado na Unidade Experimental de Plantas Forrageiras (UEPF), em área do Departamento de Produção Animal da Escola Superior de Agricultura "Luiz de Queiroz" da Universidade de São Paulo, no Município de Piracicaba, SP, localizado a $22^{\circ} 42^{\prime} 30^{\prime \prime}$ de latitude Sul, 47038'0" de longitude Oeste e $546 \mathrm{~m}$ de altitude (Ometto, 1989). O período experimental foi de 18 de agosto de 1998 a 8 de março de 1999 , com duração de 202 dias.

Conforme o sistema Köppen, o clima da região de Piracicaba pode ser classificado como Cwa, isto é, mesotérmico úmido, subtropical de inverno seco, cuja temperatura do mês mais frio é inferior a $18^{\circ} \mathrm{C}$, e a do mês mais quente ultrapassa os $22^{\circ} \mathrm{C}$ (Brasil, 1960). Os dados climáticos referentes ao período experimental encontramse na Tabela 1. Estes foram obtidos no posto meteorológico do Departamento de Ciências Exatas da ESALQ-USP, localizado a cerca de $500 \mathrm{~m}$ da área experimental.

O ensaio foi instalado em solo classificado como Terra Roxa Estruturada eutrófica, com horizonte A moderado, de textura argilosa/muito argilosa. A análise do solo $(0-20 \mathrm{~cm})$, realizada ao início da instalação do experimento, revelou $\mathrm{pH}\left(\mathrm{CaCl}_{2}\right) 5,4 ; \mathrm{MO}\left(\mathrm{g} \mathrm{kg}^{-1}\right), 37,0 ; \mathrm{P}\left(\mathrm{mg} \mathrm{dm}^{-3}\right)$, 99; $\mathrm{K}\left(\mathrm{cmol}_{\mathrm{c}}\right), 0,46 ; \mathrm{Ca}\left(\mathrm{cmol}_{\mathrm{c}}\right), 7,5 ; \mathrm{Mg}\left(\mathrm{cmol}_{\mathrm{c}}\right), 2,6$; $\mathrm{H}+\mathrm{Al}\left(\mathrm{cmol}_{\mathrm{c}}\right), 3,0 ; \mathrm{SB}\left(\mathrm{cmol}_{\mathrm{c}}\right), 10,6 ; \mathrm{T}\left(\mathrm{cmol}_{\mathrm{c}}\right), 13,6$; V (\%), 78,0. Dada a alta fertilidade, não foram realizadas práticas de calagem no momento da instalação ou durante a evolução do experimento.

Foram instalados pastos com a espécie Cynodon spp., cv. Coastcross, em março de 1996 por meio de mudas. Em virtude das adversidades climáticas e do baixo porcentual de pegamento das mudas, fez-se o replantio de algumas parcelas, durante os meses de fevereiro e março de 1997. Ao longo de 1997, foram fertilizados com $150 \mathrm{~kg} \mathrm{ha}^{-1}$ de $\mathrm{N}$ na forma de sulfato de amônio. Em 1998 receberam uma adubação com $40 \mathrm{~kg} \mathrm{ha}^{-1} \mathrm{de} \mathrm{N}$ na forma de sulfato de amônio, em janeiro, e outra, em julho. Um corte de uniformização foi realizado em março de 1998, a uma altura de cerca de $3 \mathrm{~cm}$ do nível do solo. Os animais 
foram adicionados às unidades experimentais, à medida que as alturas previstas dos tratamentos eram atingidas (a partir de maio). O período experimental iniciou-se em 18 de agosto de 1998, quando todas as unidades experimentais já haviam atingido suas alturas predeterminadas, e estendeu-se até 8 de março de 1999. Durante a condução do experimento foram realizadas quatro adubações nitrogenadas utilizando como fonte de $\mathrm{N}$ o sulfato de amônio. A primeira foi realizada em 19 de setembro (40 kg ha-1 de N); a segunda, em 21 de outubro (50 kg ha-1 de N); a terceira, em 7 de dezembro $\left(25 \mathrm{~kg} \mathrm{ha}^{-1}\right.$ de N), e a quarta, em 7 de março $\left(75 \mathrm{~kg} \mathrm{ha}^{-1}\right.$ de N). As quantidades de fertilizantes aplicadas foram calculadas a fim de que fosse conseguido um acúmulo mínimo de forragem suficiente para manter pelo menos dois animais por unidade experimental durante todo o período de avaliação

O delineamento experimental utilizado foi o de blocos completos casualizados, com quatro repetições. A cultivar Coastcross foi submetida a quatro alturas de pasto, ou seja, $5,10,15$ e $20 \mathrm{~cm}$ em relação ao nível do solo, mantidas em situação de "steady state". Cada parcela possuía cerca de $400 \mathrm{~m}^{2}$, e o controle das alturas foi realizado por meio de pastejo por ovinos, em regime de lotação contínua, e taxa de lotação variável. A altura média dos pastos foi monitorada semanalmente mediante tomada de 20 leituras em cada unidade experimental, com o "rising plate meter" ou prato ascendente, duas vezes por semana. Uma vez ao mês, era feita a calibração da altura comprimida do pasto com a altura não comprimida (régua), gerando-se, dessa forma, o valor da altura usado como referência para o monitoramento dos tratamentos. Os animais foram adicionados ou retirados das unidades experimentais conforme a necessidade de manutenção das alturas determinadas pelos tratamentos.

Para avaliação dos padrões populacionais de perfilhamento e suas respectivas taxas de natalidade e mortalidade, utilizou-se uma unidade de amostragem, representada por um anel de cano de plástico (PVC) de $15 \mathrm{~cm}$ de diâmetro e $2 \mathrm{~cm}$ de altura fixado ao solo; em cada unidade experimental existiam dois anéis. Cada amostragem foi realizada dentro de um período máximo de dois dias, e o intervalo entre amostragens foi de, aproximadamente, quatro semanas. As gerações de perfilhos foram marcadas com argolas de plástico, de cores distintas; a cada amostragem, os perfilhos pertencentes às gerações preexistentes eram contados, e os novos, marcados com uma nova cor. As densidades populacionais, os porcentuais de perfilhos nascidos, mortos e florescidos na população foram calculados da seguinte forma:

Densidade populacional $=$ número total de perfilhos existentes em todas as gerações marcadas $\left(1^{\underline{a}}+2^{\underline{a}}+3^{\underline{a}}+\ldots\right.$ $+8 \underline{\text { a }}$ gerações)

Natalidade $=100[\mathrm{n}$ o de perfilhos novos (última geração marcada) $/(n$ - total de perfilhos existentes (gerações marcadas anteriormente)]

Tabela 1. Temperaturas médias mensais do ar (máxima média, mínima média e média), precipitação pluvial e insolação diária média durante o período experimental (de agosto/98 a março/99) e valores médios nos últimos 80 anos.

\begin{tabular}{|c|c|c|c|c|c|}
\hline \multirow[t]{2}{*}{ Meses } & \multicolumn{3}{|c|}{ Temperatura $\left({ }^{\circ} \mathrm{C}\right)$} & \multirow{2}{*}{$\begin{array}{l}\text { Precipitação } \\
\text { média } \\
\text { (mm chuva) }\end{array}$} & \multirow{2}{*}{$\begin{array}{c}\text { Insolação } \\
\text { média } \\
\text { (h/dia) }\end{array}$} \\
\hline & Máxima média & Mínima média & Média & & \\
\hline Agosto/98 & 27,40 & 14,36 & 20,88 & 21,80 & 6,22 \\
\hline Média (80 anos - agosto) & 27,31 & 10,95 & 19,13 & 29,40 & 8,14 \\
\hline Setembro/98 & 27,65 & 15,29 & 21,47 & 89,30 & 5,68 \\
\hline Média ( 80 anos - setembro) & 28,06 & 13,35 & 20,70 & 63,30 & 6,83 \\
\hline Outubro/98 & 27,06 & 16,33 & 21,70 & 183,10 & 5,43 \\
\hline Média (80 anos - outubro ) & 28,90 & 15,57 & 22,23 & 111,28 & 6,87 \\
\hline Novembro/98 & 30,04 & 16,45 & 23,24 & 26,60 & 7,79 \\
\hline Média (80 anos - novembro) & 29,57 & 16,68 & 23,09 & 130,01 & 7,42 \\
\hline Dezembro/98 & 30,01 & 19,21 & 24,61 & 292,60 & 6,06 \\
\hline Média (80 anos - dezembro) & 29,61 & 18,15 & 23,87 & 200,16 & 6,58 \\
\hline Janeiro/99 & 31,42 & 18,98 & 25,20 & 210,80 & 7,70 \\
\hline Média (80 anos - janeiro) & 29,96 & 18,19 & 24,05 & 142,45 & 6,84 \\
\hline Fevereiro/99 & 30,73 & 20,05 & 25,41 & 198,30 & 5,37 \\
\hline Média (80 anos - fevereiro) & 30,23 & 19,02 & 24,61 & 185,89 & 6,54 \\
\hline Março/99 & 31,42 & 18,98 & 25,20 & 210,80 & 7,70 \\
\hline Média (80 anos - março) & 29,96 & 18,19 & 24,05 & 142,45 & 6,84 \\
\hline
\end{tabular}

Fonte: Escola Superior de Agricultura Luiz de Queiroz (1999) 
Mortalidade $=100[\mathrm{n}$ - total de perfilhos marcados nas gerações anteriores - total de perfilhos sobreviventes (última geração marcada)/no total de perfilhos marcados nas gerações anteriores]

Florescidos $=100[\mathrm{n}-$ de perfilhos florescidos (última geração marcada)/no total de perfilhos existentes (gerações marcadas anteriormente)]

As taxas de cada anel (unidade de amostragem) foram somadas, e o total dividido por 2 (dois anéis/unidade experimental), obtendo-se a estimativa média de cada unidade experimental. Foram considerados perfilhos florescidos apenas os que apresentavam a inflorescência visível.

Uma vez ao mês foi elaborada uma equação de calibração entre altura e massa de forragem, com a finalidade de relacionar a altura média do pasto com a massa de forragem existente na pastagem, bem como para o cálculo do acúmulo de matéria seca. Para esta calibração foram escolhidos dois pontos de cada unidade experimental, sendo estes correspondentes aos de maior e menor altura, a fim de se obter as maiores amplitudes possíveis de massa de forragem. As medidas com régua e prato ascendente foram tomadas dentro de um círculo com $0,25 \mathrm{~m}^{2}$ de área, alocado em cada ponto previamente escolhido Em seguida, a forragem era cortada no nível do solo (utilizando-se tosquiadeira elétrica para ovinos), lavada para eliminação de resíduos de terra e fezes e secada em estufa a $65^{\circ} \mathrm{C}$ até massa constante e pesada. Assim, após determinada a massa seca, estabeleceu-se, mediante regressão linear, a relação entre altura e massa de forragem, a cada mês. A partir da obtenção das equações de calibração, fo possível calcular as massas de forragem presentes em cada período de avaliação, bem como o acúmulo de forragem de forma indireta, utilizando-se somente a altura da régua ou do prato ascendente

O acúmulo de forragem foi medido utilizando-se gaiolas de exclusão, em número de três por parcela, compreendendo uma área de, aproximadamente, $0,5 \mathrm{~m}^{2}(70 \mathrm{~cm} \mathrm{x}$ $70 \mathrm{~cm} \times 70 \mathrm{~cm}$ ) cada, e observando-se um intervalo de 21 dias entre amostragens sucessivas. Após a amostragem, as gaiolas eram rotacionadas nas unidades experimentais e fixadas em novos pontos representativos da sua condição (altura média) no momento do rodízio.

$\mathrm{O}$ acúmulo de forragem foi estimado utilizando-se o método agronômico da diferença, conforme a equação (Davies et al., 1993):

$\mathrm{AF}=\mathrm{MFf}-\mathrm{MFi}$,

onde:

AF: acúmulo de forragem;

MFf: massa de forragem sob a gaiola, no último dia da exclusão (dia 21);
Mfi: média da massa de forragem na unidade experimental no dia da colocação das gaiolas (dia 0 ).

Os dados foram analisados utilizando-se o procedimento GLM (General Linear Models) do pacote estatístico SAS (Statistical Analysis System), versão 6.12 para Windows. Dentro deste procedimento, optou-se pelo subprocedimento de medidas repetidas no tempo (Repeated Measures), uma vez que todas as variáveis em estudo foram coletadas ao longo de oito meses (SAS Institute, 1988) Desta forma foi possível detectar os efeitos das causas de variação principais (bloco, altura), as interações entre elas (bloco x altura), além dos efeitos de tempo dentro de cada uma das causas de variação principais (tempo, tempo x bloco, tempo x altura)

Todos os conjuntos de dados foram testados, antes da análise geral global, com a finalidade de assegurar que as quatro prerrogativas básicas da análise de variância (aditividade do modelo, independência dos erros, normalidade dos dados e homogeneidade das variâncias) estavam sendo respeitadas. Utilizou-se o LSMEANS para comparação de médias entre tratamentos.

\section{Resultados e Discussão}

Quanto às taxas de natalidade, os resultados obtidos revelaram que houve efeito de época de coleta de dados $(\mathrm{P}=0,0037)$, porém não houve efeito da altura do pasto $(\mathrm{P}>0,10)$ (Tabela 2). As maiores taxas foram verificadas durante os meses de verão (janeiro e fevereiro), seguidas pelas referentes aos meses de final de inverno (agosto e setembro), e as menores, durante a primavera (outubro, novembro e dezembro). Este padrão de comportamento provavelmente deveu-se às melhorias das condições de ambiente, como temperatura, regime pluviométrico e insolações diárias verificadas durante os meses de verão (janeiro e fevereiro) em relação às referentes ao período de final de inverno e início de primavera, uma vez que esses fatores de ambiente influenciam 0 surgimento e desenvolvimento das gemas localizadas nas porções basais e laterais das plantas (Langer, 1956).

As diferenças entre taxas de natalidade observadas quanto às alturas do pasto estudadas foram variáveis durante a fase experimental, porém não apresentaram qualquer tendência de maiores ou menores taxas para determinadas alturas (Tabela 2). Estes resultados corroboram os encontrados por L'Huillier (1987), nos quais o autor também não verificou a 
existência de diferenças nas taxas de natalidade de perfilhos quando testou tratamentos de intensidades de pastejo. Talvez este comportamento seja uma conseqüência de o perfilhamento constituir-se em uma resposta a mudanças de temperatura (Gillet et al., 1984) e regimes de luz (Mitchell, 1953), além de ser controlado pela taxa de aparecimento de folhas, que é insensível à desfolha (Matthew et al., 1999). Outra possibilidade seria a grande variabilidade inerente a esse tipo de avaliação (Davies, 1981).

Houve efeito do período da coleta de dados $(\mathrm{P}=0,0197)$, altura do pasto $(\mathrm{P}=0,0345)$ e interação tempo x altura $(\mathrm{P}=0,0087)$ nas taxas de mortalidade. As maiores taxas foram observadas durante o verão (6ㅇ e 7 o período), com uma taxa média de $50 \%$, se-

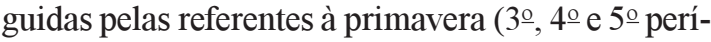
odo), com taxa média de $45 \%$, e as menores, durante o final do inverno, apresentando uma média de $37 \%$ de mortalidade de perfilhos. Estes resultados, em associação com os de natalidade (Tabela 2), revelam uma grande renovação ("turnover") de perfilhos durante os meses de verão. Assim, práticas de manejo que assegurem altas taxas de natalidade durante 0 verão tornam-se essenciais para a manutenção e/ou incremento da densidade populacional de perfilhos durante as estações de outono, inverno e primavera.
É provável que as altas taxas de mortalidade, bem como as baixas taxas de natalidade verificadas principalmente durante P5 (Tabela 2) na primavera, sejam conseqüência do déficit hídrico ocorrido durante o mês de novembro (Tabela 1). Estes resultados estão de acordo com os descritos por Korte et al. (1982), em que condições de seca provocaram elevações nas taxas de mortalidade de perfilhos. Já em outro ensaio de corte com irrigação tal fato não ocorreu (Korte, 1986).

Quanto às alturas do pasto, verifica-se que somente ocorreram diferenças no 5 o e 6 o período (Tabela 2). Contudo, os maiores valores médios observados durante o período experimental foram constatados nas menores alturas de pasto $(5$ e $10 \mathrm{~cm})$, o que revela a necessidade de maiores taxas de natalidade para essas alturas a fim de assegurar a manutenção das densidades populacionais na pastagem. Os resultados deste experimento confirmam os encontrados por L'Huillier (1987), que somente verificaram efeitos das maiores intensidades de pastejo sobre as taxas de mortalidade mas não sobre as de natalidade de perfilhos.

Em relação ao florescimento, houve apenas efeito de período de coleta de dados $(\mathrm{P}=0,0132)$, sendo constatado um elevado grau de variabilidade dos

Tabela 2. Taxas de natalidade e mortalidade de perfilhos em pastagens de Cynodon spp. cv. Coastcross submetidas a quatro intensidades de desfolha, em diferentes períodos ${ }^{(1)}$

\begin{tabular}{|c|c|c|c|c|c|c|}
\hline \multirow[t]{2}{*}{ Período } & \multicolumn{4}{|c|}{ Altura do pasto $(\mathrm{cm})$} & \multirow[t]{2}{*}{ Médias } & \multirow{2}{*}{$\begin{array}{l}\text { Erro-padrão } \\
\text { da média }\end{array}$} \\
\hline & 5 & 10 & 15 & 20 & & \\
\hline & \multicolumn{6}{|c|}{ - } \\
\hline $18 / 8$ a $15 / 9 / 98$ & $57,1 \mathrm{ab}$ & $32,8 b$ & $88,2 \mathrm{a}$ & $67,8 \mathrm{ab}$ & 61,5 & 14,6 \\
\hline $15 / 9$ a $16 / 10 / 98$ & $47,4 \mathrm{a}$ & $59,7 \mathrm{a}$ & $42,8 \mathrm{a}$ & $37,1 \mathrm{a}$ & 46,8 & 10,1 \\
\hline $16 / 10$ a $13 / 11 / 98$ & $70,2 \mathrm{a}$ & $60,3 \mathrm{a}$ & $67,1 \mathrm{a}$ & $45,3 \mathrm{a}$ & 60,7 & 15,2 \\
\hline $13 / 11$ a $8 / 12 / 98$ & $37,9 a$ & $36,0 \mathrm{a}$ & $33,4 \mathrm{a}$ & $33,9 a$ & 35,3 & 9,1 \\
\hline 8/12 a 11/1/99 & $19,7 \mathrm{~b}$ & $21,1 b$ & $38,5 \mathrm{a}$ & $20,9 b$ & 25,1 & 5,4 \\
\hline $11 / 1$ a 3/2/99 & $91,6 a$ & $45,5 b$ & $60,1 b$ & $64,6 a$ & 65,5 & 11,8 \\
\hline $3 / 2$ a 8/3/99 & $78,7 \mathrm{a}$ & $83,0 \mathrm{a}$ & $64,4 \mathrm{a}$ & $93,1 \mathrm{a}$ & 79,8 & 16,3 \\
\hline \multicolumn{7}{|c|}{ - } \\
\hline $18 / 8$ a $15 / 9 / 98$ & $48,5 \mathrm{a}$ & $51,5 \mathrm{a}$ & $35,1 \mathrm{a}$ & $36,4 \mathrm{a}$ & 42,9 & 7,6 \\
\hline $15 / 9$ a $16 / 10 / 98$ & $29,6 \mathrm{a}$ & $30,4 a$ & $31,4 \mathrm{a}$ & $27,6 \mathrm{a}$ & 29,7 & 3,6 \\
\hline $16 / 10$ a $13 / 11 / 98$ & $60,4 \mathrm{a}$ & $51,7 \mathrm{~b}$ & $48,3 \mathrm{a}$ & $46,9 \mathrm{a}$ & 51,8 & 5,3 \\
\hline 13/11 a 8/12/98 & $40,4 \mathrm{a}$ & $31,2 b$ & $41,7 \mathrm{a}$ & $32,8 \mathrm{a}$ & 36,5 & 5,1 \\
\hline 8/12 a 11/1/99 & $65,9 \mathrm{a}$ & $42,0 \mathrm{~b}$ & $45,4 \mathrm{~b}$ & $38,7 \mathrm{~b}$ & 48,0 & 4,8 \\
\hline $11 / 1$ a 3/2/99 & $65,9 a$ & $43,2 b$ & $36,8 b$ & $39,7 b$ & 46,4 & 5,5 \\
\hline $3 / 2$ a 8/3/99 & $60,8 \mathrm{a}$ & $52,8 \mathrm{a}$ & $53,7 \mathrm{a}$ & $47,5 \mathrm{a}$ & 53,7 & 6,3 \\
\hline
\end{tabular}

${ }^{(1)}$ Médias na mesma linha seguidas da mesma letra não diferem entre si ( $\mathrm{P}>0,10$, LSMEANS). 
dados (Tabela 3). As maiores proporções de perfilhos florescidos foram verificadas durante os meses de final de inverno (agosto e setembro), seguidas pelas referentes aos meses de primavera (outubro, novembro e dezembro), e as menores, durante a estação do verão (janeiro, fevereiro e março) (Tabela 3). Provavelmente as maiores proporções constatadas no final do inverno e na primavera promoveram condições desfavoráveis ao nascimento de novos perfilhos, pois durante a fase do desenvolvimento reprodutivo as reservas metabólicas acumuladas pelas plantas em períodos anteriores são destinadas a este evento, criando uma forte competição com os centros ativos de crescimento das plantas (gemas), que também dependem delas para se desenvolver (Jewiss, 1972). Já as altas taxas de mortalidade observadas durante o verão (Tabela 2) podem ser relacionadas com o final da vida dos perfilhos que tiveram seu desenvolvimento reprodutivo completado durante o final do inverno e primavera, uma vez que os perfilhos morrem algum tempo após florescerem como resultado do mecanismo natural de seu ciclo de vida (Langer, 1956).

Os tratamentos com as menores alturas de pasto levaram à constatação das menores proporções mé- dias de florescimento durante todo o período experimental, provavelmente como conseqüência direta das maiores intensidades de desfolha exercidas por maiores taxas de lotação médias nesses pastos (Mazzanti \& Lemaire, 1994). Estes resultados corroboram os verificados por Korte et al. (1984), em que os referidos autores constataram menores proporções de perfilhos reprodutivos para tratamentos com maiores taxas de lotação.

Quanto à dinâmica e densidade populacional de perfilhos, foram constatados efeitos referentes a período de coleta de dados $(\mathrm{P}=0,0530)$ e altura do pasto $(\mathrm{P}=0,0186)$, os quais podem ser verificados na Tabela 3. Considerando a distribuição das densidades populacionais de perfilhos durante o período experimental, verifica-se que nelas ocorreu uma grande elevação, do final do inverno (agosto) até meados da primavera (novembro). Esse padrão de perfilhamento pode ser justificado pelas melhorias das condições ambientais, como temperatura, luminosidade e pluviosidade (Tabela 1), juntamente com os reconhecidos benefícios causados pelas fertilizações nitrogenadas durante esse período (Langer, 1956; Gautier et al., 1999). Já em dezembro, observa-se uma queda no número de perfilhos, em virtude

Tabela 3. Florescimento e densidade populacional de perfilhos em pastagens de Cynodon spp. cv. Coastcross submetidas a quatro intensidades de desfolha, em diferentes épocas ${ }^{(1)}$

\begin{tabular}{|c|c|c|c|c|c|c|}
\hline \multirow[t]{2}{*}{ Período } & \multicolumn{4}{|c|}{ Altura do pasto $(\mathrm{cm})$} & \multirow[t]{2}{*}{ Médias } & \multirow{2}{*}{$\begin{array}{c}\text { Erro-padrão } \\
\text { da média }\end{array}$} \\
\hline & 5 & 10 & 15 & 20 & & \\
\hline & \multicolumn{6}{|c|}{ Florescimento (\%) } \\
\hline $18 / 8$ a $15 / 9 / 98$ & $5,6 \mathrm{a}$ & $7,5 \mathrm{a}$ & $5,9 \mathrm{a}$ & $5,7 \mathrm{a}$ & 6,2 & 2,3 \\
\hline $15 / 9$ a $16 / 10 / 98$ & $0,6 \mathrm{a}$ & $2,5 \mathrm{a}$ & $2,8 \mathrm{a}$ & $0,4 \mathrm{a}$ & 1,6 & 1,4 \\
\hline $16 / 10$ a $13 / 11 / 98$ & $3,9 \mathrm{a}$ & $0,1 \mathrm{~b}$ & $3,3 \mathrm{ab}$ & $2,9 \mathrm{ab}$ & 2,5 & 1,4 \\
\hline $13 / 11$ a $8 / 12 / 98$ & $0,0 \mathrm{~b}$ & $0,8 \mathrm{ab}$ & $1,7 \mathrm{ab}$ & $2,6 \mathrm{a}$ & 1,3 & 0,7 \\
\hline $8 / 12$ a $11 / 1 / 99$ & $0,0 \mathrm{a}$ & $0,0 \mathrm{a}$ & $0,0 \mathrm{a}$ & $0,0 \mathrm{a}$ & 0,0 & 0,0 \\
\hline $11 / 1$ a 3/2/99 & $0,0 \mathrm{a}$ & $1,1 \mathrm{a}$ & $0,8 \mathrm{a}$ & $1,3 \mathrm{a}$ & 0,8 & 0,5 \\
\hline \multirow[t]{2}{*}{$3 / 2$ a $8 / 3 / 99$} & $0,0 \mathrm{a}$ & $0,0 \mathrm{a}$ & $0,0 \mathrm{a}$ & $0,2 \mathrm{a}$ & 0,0 & 0,1 \\
\hline & \multicolumn{6}{|c|}{ Densidade populacional (perfilhos $/ \mathrm{m}^{2}$ ) } \\
\hline $18 / 8$ a $15 / 9 / 98$ & $10.250 \mathrm{a}$ & $6.860 \mathrm{~b}$ & $5.130 \mathrm{~b}$ & $5.440 b$ & 6.920 & 727 \\
\hline $15 / 9$ a 16/10/98 & $11.350 \mathrm{a}$ & $5.570 \mathrm{~b}$ & $6.540 \mathrm{~b}$ & $7.040 \mathrm{~b}$ & 7.625 & 711 \\
\hline $16 / 10$ a $13 / 11 / 98$ & $13.030 \mathrm{a}$ & $7.540 \mathrm{~b}$ & $7.190 \mathrm{~b}$ & $7.480 \mathrm{~b}$ & 8.810 & 1.099 \\
\hline $13 / 11$ a $8 / 12 / 98$ & $13.420 \mathrm{a}$ & $7.580 \mathrm{~b}$ & $8.030 \mathrm{~b}$ & $7.520 b$ & 9.138 & 945 \\
\hline $8 / 12$ a $11 / 1 / 99$ & $13.060 \mathrm{a}$ & $7.460 \mathrm{~b}$ & $7.320 \mathrm{~b}$ & $7.330 \mathrm{~b}$ & 8.793 & 981 \\
\hline $11 / 1$ a 3/2/99 & $6.780 \mathrm{a}$ & $9.220 \mathrm{a}$ & $6.710 \mathrm{a}$ & $5.880 \mathrm{a}$ & 7.148 & 1.670 \\
\hline $3 / 2$ a $8 / 3 / 99$ & $8.510 \mathrm{a}$ & $5.940 \mathrm{a}$ & $7.850 \mathrm{a}$ & $7.420 \mathrm{a}$ & 7.430 & 1.153 \\
\hline
\end{tabular}

${ }^{(1)}$ Médias na mesma linha seguidas da mesma letra não diferem entre si ( $\mathrm{P}>0,10$, LSMEANS). 
das menores taxas de natalidade e maiores taxas de mortalidade verificadas em dezembro (5o período) (Tabela 2). Estas, por sua vez, podem ter sido conseqüência da seca ocorrida durante o mês de novembro. As densidades populacionais de perfilhos somente voltaram a se elevar na última data de observação (março), provavelmente em virtude das baixas insolações durante o mês de fevereiro (Tabela 1), uma vez que a luminosidade é considerada o fator de ambiente que mais interfere na intensidade do perfilhamento (Gautier et al., 1999). Juntamente com isso, durante o 4ㅇ e 5o período as taxas de mortalidade foram capazes de superar as taxas de natalidade, levando a uma conseqüente queda no número de perfilhos em períodos subseqüentes. Já durante os períodos 6 e 7, as taxas de natalidade foram maiores que as de mortalidade, levando a um incremento na densidade populacional em agosto (Tabela 3 ).

Quanto às alturas do pasto, verifica-se que as maiores densidades populacionais ocorreram em pastos mantidos baixos $(5 \mathrm{~cm})$ até o 5 período. Já nos períodos 6 e 7 não houve diferença $(\mathrm{P}>0,10)$ entre tratamentos, provavelmente em razão das maiores taxas de mortalidade e menores taxas de natalidade observadas durante o período 5 com relação ao tratamento de $5 \mathrm{~cm}$ em relação aos demais (Tabela 2). Durante os períodos 6 e 7, as taxas de natalidade referentes ao tratamento de $5 \mathrm{~cm}$ foram superiores às de mortalidade de forma mais acentuada que para os demais tratamentos, levando à superioridade em número de perfilhos observada no período 8 (Tabela 3 ). A verificação de um maior número de perfilhos nos tratamentos de maior intensidade de desfolha deve-se à existência de um mecanismo de compensação tamanho/densidade populacional de perfilhos, existente em comunidades de plantas, em que os pastos mantidos baixos apresentam maior população de perfilhos menores em relação aos pastos mantidos altos, e vice-versa (Matthew et al., 1995).

Considerando o total de perfilhos existentes ao final do verão (em março), verifica-se que a participação dos perfilhos formados durante o final do inverno (agosto e setembro) correspondeu a apenas $3 \%$, e os formados durante a primavera (outubro, novembro e dezembro) representaram $10 \%$. Já os perfilhos originados durante o verão (janeiro, fevereiro e março) equivaleram a $86 \%$ do total verificado nesta última data de avaliação. Este padrão de comportamento revela a existência de uma alta renovação ("turnover") da população de perfilhos durante o verão, principalmente ao final dessa estação, uma vez que somente os perfilhos formados em março corresponderam a $63 \%$ do total de perfilhos existentes por ocasião da última avaliação. Isto significa que práticas de manejo que visem à manutenção ou mesmo ao incremento das densidades populacionais de perfilhos em pastos de coastcross durante as estações do outono e inverno devam permitir a ocorrência de altas natalidades de perfilhos durante a estação do verão, especialmente no final

Em relação às taxas de acúmulo de forragem, houve efeito apenas de período de coleta $(\mathrm{P}=0,0110)$ (Tabela 4). As maiores taxas foram verificadas durante a estação do verão (janeiro, fevereiro e março), com

Tabela 4. Taxas de acúmulo de matéria seca $\left(\mathrm{kg} \mathrm{MS} \mathrm{ha}^{-1} \mathrm{dia}^{-1}\right)$ em pastagens Cynodon spp. cv. Coastcross submetidas a quatro intensidades de desfolha, em diferentes épocas ${ }^{(1)}$.

\begin{tabular}{lcccccc}
\hline \multirow{2}{*}{ Mês } & \multicolumn{9}{c}{ Altura do pasto $(\mathrm{cm})$} & Médias & $\begin{array}{c}\text { Erro-padrão } \\
\text { da média }\end{array}$ \\
\cline { 2 - 5 } & 5 & 10 & 15 & 20 & & 9,3 \\
\hline Agosto & $44,1 \mathrm{a}$ & $45,5 \mathrm{a}$ & $29,7 \mathrm{a}$ & $40,8 \mathrm{a}$ & 40,0 & 5,1 \\
Setembro & $38,0 \mathrm{a}$ & $31,4 \mathrm{a}$ & $35,9 \mathrm{a}$ & $36,1 \mathrm{a}$ & 35,3 & 13,0 \\
Outubro & $80,7 \mathrm{a}$ & $78,9 \mathrm{a}$ & $61,0 \mathrm{a}$ & $59,9 \mathrm{a}$ & 70,1 & 11,0 \\
Novembro & $47,1 \mathrm{a}$ & $44,8 \mathrm{a}$ & $51,9 \mathrm{a}$ & $59,2 \mathrm{a}$ & 50,7 & 16,7 \\
Dezembro & $83,7 \mathrm{a}$ & $85,5 \mathrm{a}$ & $81,0 \mathrm{a}$ & $87,3 \mathrm{a}$ & 84,4 & 10,2 \\
Janeiro & $96,9 \mathrm{a}$ & $100,1 \mathrm{a}$ & $87,4 \mathrm{a}$ & $78,1 \mathrm{a}$ & 90,6 & 11,6 \\
Fevereiro & $96,5 \mathrm{a}$ & $85,6 \mathrm{a}$ & $96,9 \mathrm{a}$ & $85,5 \mathrm{a}$ & 91,1 & 20,9 \\
Março & $95,4 \mathrm{a}$ & $94,0 \mathrm{a}$ & $103,0 \mathrm{a}$ & $91,8 \mathrm{a}$ & 96,0 & \\
\hline
\end{tabular}

${ }^{(1)}$ Médias na mesma linha seguidas da mesma letra minúscula não diferem entre si ( $\mathrm{P}>0,10$, LSMEANS) 
média de $93 \mathrm{~kg} \mathrm{ha}^{-1} \mathrm{dia}^{-1}$, seguida pelas referentes à primavera (outubro, novembro e dezembro), com média de $68 \mathrm{~kg} \mathrm{ha}^{-1} \mathrm{dia}^{-1}$, e as menores, no final do inverno, ou seja, uma taxa média de $38 \mathrm{~kg} \mathrm{ha}^{-1} \mathrm{dia}^{-1}$. Associando esses resultados aos referentes às densidades populacionais de perfilhos, verifica-se baixa correlação $(r=0,23)$ entre ambas as variáveis ao longo do período experimental, pois em alguns meses foram verificadas baixas densidades populacionais, gerando altas taxas de acúmulo de matéria seca e viceversa. Este comportamento revela que nem sempre o número de perfilhos é o principal determinante da massa de forragem acumulada durante um determinado período, mas sim uma combinação entre o número e peso de perfilhos (Matthew et al., 1999). A seca ocorrida durante o mês de novembro provavelmente foi a causa da queda verificada nas taxas de acúmulo de forragem daquele mês. Porém, o número de perfilhos somente decresceu nas contagens referentes aos meses de dezembro e janeiro, o que revela um atraso na queda da densidade populacional de perfilhos em relação ao acúmulo de forragem (Tabelas 3 e 4). Esse padrão de resposta é semelhante ao relatado por Grant \& King (1983), em que se constatou uma defasagem de tempo entre os ajustes em densidade populacional e peso por perfilho. Naquelas condições, variações em peso por perfilho ocorreram mais cedo que os ajustes correspondentes em número de perfilhos.

Apesar de não terem sido observadas diferenças entre os tratamentos quanto às taxas de acúmulo de forragem (Tabela 4), estas provavelmente existiram. Tal afirmativa considera o fato de o método utilizado para mensuração do acúmulo de forragem (gaiolas de exclusão) permitir uma superestimativa da quantidade de forragem nos pastos mais baixos e uma subestimativa nos pastos mais altos (Frame, 1981). Segundo Frame (1981), pastos mantidos baixos possuem grande quantidade de perfilhos pequenos e uma baixa interceptação de luz (Matthew et al., 1995). Quando estes são isolados da ação do animal, crescem em tamanho sem haver redução proporcional na densidade de perfilhos durante um período de três a quatro semanas, ou seja, há uma defasagem de tempo entre o sinal de competição por luz e a morte dos perfilhos para um novo equilíbrio. Durante esse período, portanto, estimativas de acúmulo são inflacionadas. Já em pastos mais altos, a interceptação de luz encontra-se mais próxima de valores elevados, diferentemente dos pastos mais baixos, causando uma subestimativa de suas taxas de acúmulo quando isolados do animal, uma vez que o IAF teto é atingido muito rapidamente.

\section{Conclusões}

1. As condições de ambiente são determinantes básicos da distribuição das densidades populacionais de perfilhos ao longo das estações do ano

2. Práticas de manejo devem ser idealizadas a fim de assegurar altas taxas de natalidade durante o verão, em face da existência de um período de alta renovação ("turnover") de perfilhos observada.

3. O mecanismo de compensação tamanho/densidade populacional de perfilhos manifesta-se de forma intensa durante a maior parte do período experimental.

\section{Agradecimentos}

À Fundação de Amparo à Pesquisa do Estado de São Paulo (FAPESP), pela concessão de bolsa de mestrado durante o período experimental.

\section{Referências}

BRASIL. Ministério da Agricultura. Serviço Nacional de Pesquisa Agronômica. Comissão de Solos. Levantamento de reconhecimento dos solos do estado de São Paulo. Rio de Janeiro, 1960. 634 p. (Boletim, 12).

CHAPMAN, D. F.; CLARK, D. A.; LAND, C. A.; DYMOCK, N. Leaf and tiller or stolon death in Lolium perene, Agrostis spp. and Trifolium repens in set stocked and rotationally grazed hill pastures. New Zealand Journal of Agricultural Research, Wellington, v. 27, p. 303-312, 1984.

COLVILL, K. E.; MARSHALL, C. Tiller dynamics and assimilate partitioning in Lolium perenne with particular reference to flowering. Annals of Applied Biology, Wellesbourne, v. 104, p. 543-557, 1984

DAVIES, A. Tissue turnover in the sward. In: HODGSON, J.; BAKER, R. D.; DAVIES, A.; LAIDLAW, A. S.; LEAVER, J. D. (Ed.). Sward measurement handbook. Berkshire : British Grassland Society, 1981. p. 179-208. 
DAVIES, D. A.; FORTHERGILL, M.; MORGAN, C. T. Assessment of contrasting perennial ryegrass, with and without white clover, under continuous sheep stocking in the uplands. 5. Herbage production, quality and intake in years 4-6. Grass and Forage Science, Oxford, v. 48, p. 213-222, 1993

ESCOLA SUPERIOR DE AGRICULTURA LUIZ DE QUEIROZ. Departamento de Ciências Exatas. Médias mensais e total de chuvas. URL: http://www.ciagri.usp.br/ > emdabreu/MEDIAS.TXT. Consultado em 20 set. 1999.

FRAME, J. Herbage mass. In: HODGSON, J.; BAKER, R. D.; DAVIES, A.; LAIDLAW, A. S.; LEAVER, J. D. (Ed.). Sward measurement handbook. Berkshire : British Grassland Society, 1981. p. 39-67.

GAUTIER, H.; VARLET-GRANCHER, C.; HAZARD, L Tillering responses to the light environment and to the defoliation in populations of perennial ryegrass (Lolium perenne L.) selected for contrasting leaf length. Annals of Botany, London, v. 83, p. 423-429, 1999.

GILLET, M.; LEMAIRE, G.; GOSSE, G. Essai d'élaboration d'un schéma global de croissance des graminées fourragères. Agronomie, Paris, v. 4, p. 75-82, 1984

GRANT, S. A.; KING, J. Grazing management and pasture production: the importance of sward morphological adaptations and canopy photosynthesis. In: THE HILL FARMING RESEARCH ORGANISATION (Edinburgh, Escócia). Biennial report: 1982-83. Palmerston North, 1983. p. 119-129.

HODGSON, J. Herbage production and utilization. In HODGSON, J. (Ed.). Grazing management: science into practice. New York : J. Wiley, 1990. p. 38-54

JEWISS, O. R. Tillering in grasses: its significance and control. British Grassland Society Journal, Oxford, v. 27, p. 65-82, 1972.

KORTE, C. J. Tillering in 'Grasslands Nui' perennial ryegrass swards. 2. Seasonal pattern of tillering and age of flowering tillers with two mowing frequencies. New Zealand Journal of Agricultural Research, Wellington, v. 29 , p. $629-638,1986$

KORTE, C. J.; WATKIN, B. R.; HARRIS, W. Effects of the timing and intensity of spring grazing on reproductive development, tillering, and herbage production of perennial ryegrass dominant pasture. New Zealand Journal of Agricultural Research, Wellington, v. 27, p. 135-149, 1984

KORTE, C. J.; WATKIN, B. R.; HARRIS, W. Use of residual leaf area index and light interception as criteria of spring-grazing management of a ryegrass dominant pasture. New Zealand Journal of Agricultural Research, Wellington, v. 25, p. 309-319, 1982

LANGER, R. H. M. Growth and nutrition of Timothy Annals of Applied Biology, Wellesbourne, v. 44, p. $166-187,1956$.

LANGER, R. H. M. Tillering in herbage grass: a review. Herbage Abstracts, Wallingford, v. 33, p. 141-148, 1963

L'HUILLIER, P. J. Tiller appearance and death of Lolium perenne in mixed swards grazed by dairy cattle at two stocking rates. New Zealand Journal of Agricultural Research, Wellington, v. 30, p. 15-22, 1987

MATTHEW, C.; ASSUERO, S. G.; BLACK, C. K.; HAMILTON, N. R. S. Tiller dynamics of grazed swards In: SIMPÓSIO INTERNACIONAL DE ECOFISIOLOGIA DE PLANTAS FORRAGEIRAS E ECOLOGIA DO PASTEJO, 1., Curitiba, 1999. Anais... Curitiba : UFPR, 1999. p. 109-133

MATTHEW, C.; LEMAIRE, G.; HAMILTON, N. R. S.; HERNANDEZ-GARAY, A. A modified self-thinning equation to describe size/density relationships for defoliated swards. Annals of Botany, London, v. 76, p. $579-587,1995$.

MAZZANTI, A.; LEMAIRE, G. Effect of nitrogen fertilization upon herbage production of tall fescue swards continuously grazed by sheep. 1. Herbage growth dynamics. Grass and Forage Science, Oxford, v. 49, p. $111-120,1994$.

MITCHELL, K. J. Influence of light and temperature on the growth of ryegrass (Lolium spp.). 2. The control of lateral bud development. Physiologia Plantarum, Copenhagen, v. 6, p. 425-443, 1953.

OMETTO, J. C. Registros e estimativas dos parâmetros meteorológicos da região de Piracicaba, SP. Piracicaba : FEALQ, 1989. 76 p.

SAS INSTITUTE (Cary, Estados Unidos). SAS user's guide: release 6.03. Cary, 1988. $1028 \mathrm{p}$

SILVA, S. C. da. A study of spring grazing management effect on summer-autumn pasture and milk production of perennial ryegrass $x$ white clover dairy swards Palmerston North : Massey University,1994. 217 p. Ph.D. Thesis.

SILVA, S. C. da; PEDREIRA, C. G. S. Princípios de ecologia aplicados ao manejo da pastagem. In: SIMPÓSIO SOBRE ECOSISTEMA DE PASTAGENS, 3., 1997, Jaboticabal. Anais... Jaboticabal : FUNEP, 1997. p. 1-62. 